\title{
Increased Surface Tension Favors Pulmonary Edema Formation in Anesthetized Dogs' Lungs
}

\author{
Richard K. Albert, S. LaKshminarayan, Jacob Hildebrandt, Wayne Kirk, \\ and John ButLer, Medical Service, Veterans Administration Hospital, \\ Seattle, Washington 98108; Department of Medicine, University of Washington, \\ Seattle, Washington 98195
}

A B S TRACT The possibility that surface tension may affect the hydrostatic transmural pressure of pulmonary vessels and the development of pulmonary edema was studied in anesthetized, open-chested dogs. Isogravimetric pressure (the static intravascular pressure at which transmural osmotic and hydrostatic pressures are balanced such that net fluid flux is zero and lung weight is constant) was measured in nine animals under three conditions: $(a)$ control, normal surface tension, at an alveolar pressure of $30 \mathrm{~cm} \mathrm{H}_{2} \mathrm{O}$ with the apenic lung at room temperature; $(b)$ after increasing surface tension by cooling and ventilating at a low functional residual capacity, at an alveolar pressure sufficient to produce the same lung volume present during control measurements; and $(c)$ after restoring surface tension by rewarming while holding the lung at a high inflation volume, again at the control lung volume. Lung volumes were established from external dimensions and confirmed $\pm 10 \%$ by deflation spirometry. The isogravimetric pressure (relative to alveolar pressure) was significantly less with increased surface tension than during either the initial control condition $(P<0.01)$, or when the surface tension has been restored $(P<0.01)$. Similar changes occurred in each of three additional studies performed with control alveolar pressures of $10 \mathrm{~cm} \mathrm{H}_{2} \mathrm{O}$. Thus, increased surface tension favors fluid leakage presumably because it increases the microvascular transmural pressure.

\section{INTRODUCTION}

Fluid balance in the lung has been described by the Starling equation where net fluid flux is directly related to the hydrostatic and oncotic pressure difference between the pulmonary microvasculature and the perimicrovascular space. Perimicrovascular fluid pressure

Received for publication 6 October 1978 and in revised form 22 December 1978.
$(\mathrm{Ppmv})^{1}$ could affect the alveolar vessel transmural pressure and therefore the fluid exchange in the alveolar wall (1). Surface tension apparently affects the perimicrovascular total pressure because pulmonary perfusion was shown to be facilitated in an air-filled lung compared with a fluid-filled lung (2). Others have shown that for a constant pulmonary blood flow, perfusion pressure measured relative to alveolar pressure(s) (Palv) was lower on inflation than when arriving at the same lung volume by deflation $(3,4)$.

Pattle (5) first suggested that a low surface tension might be needed to prevent the surface forces of the alveolar lining layer from causing continuous transudation of fluid into the alveoli with resultant pulmonary edema. Clements (6) postulated that with an increase in alveolar surface tension caused by surfactant depletion, Ppmv might become more negative. This would increase the microvascular hydrostatic gradient and therefore enhance filtration. However, this concept has never been demonstrated experimentally. The following study was done to determine if increasing alveolar surface tension favors pulmonary edema formation.

\section{METHODS}

Adult mongrel dogs of either sex weighing from 20 to $26 \mathrm{~kg}$ were used. The Helsinki accords against animal cruelty were followed. The dogs were anesthetized with pentobarbital sodium $(25 \mathrm{mg} / \mathrm{kg})$, followed by $\alpha$-choralose in propylene glycol $(70 \mathrm{mg} / \mathrm{kg}$ ) and aqueous urethane $(350 \mathrm{mg} / \mathrm{kg})$. They were placed in the right lateral decubitus position. The left hemithorax was opened by an incision extending from the paraspinous muscle along the fourth intercostal space to the sternum, down the left parasternal line to the diaphragm, and along the diaphragmatic reflections back to the paraspinous muscles. This flap, made up of the left thoracic wall, was retracted sufficiently to completely expose the left lung.

\footnotetext{
${ }^{1}$ Abbreviations used in this paper: FRC, functional residual capacities; Palv, alveolar pressure(s); Pisog, isogravimetric pressure; Ppa, pulmonary arterial pressure; Ppmv, perimicrovascular fluid pressure; Ppv, venous pressure.
} 
The dogs were then turned to the supine position. The lingula was excised. Cannulae were tied into the left pulmonary artery, and, through the left atrial appendage, into the left pulmonary vein. This likely interfered with lymphatic drainage. Left pulmonary arterial (Ppa) and venous (Ppv) pressures were controlled by the levels of heparinized, autologous whole blood in reservoirs connected to the cannulae. A tracheal divider allowed maintenance of normal arterial blood gases by ventilating the right lung with an animal respirator (Harvard Apparatus Co., Inc., Millis, Mass.). The left lung was distended with $6 \% \mathrm{CO}_{2}$ and air at different Palv after initial distension to Palv $=35 \mathrm{~cm} \mathrm{H}_{2} \mathrm{O}$. The experimental left lower lobe was placed in a fabric net and suspended from a strain gauge for continual weight recording (Grass force-displacement transducer, model FT036, Grass Instrument Co., Quincy, Mass.). Vascular pressures were calibrated with the bottom of the lung as zero reference. At all times, Ppa and Ppv were identical. Lobar volumes were estimated by measuring external dimensions in three planes with pelvimetry forceps. Dimensional changes were calibrated in terms of lobar volume change measured by deflation spirometry after uniform volume histories. This method was capable of detecting volume changes of $<10 \%$.

Faridy et al. (7) and Nagao et al. (8) inferred that surface tension was increased when cooled, excised lungs were ventilated at high tidal volumes from low functional residual capacities (FRC) because compliance was reduced without corresponding changes in tissue properties. Although surface properties were never actually measured directly, this suggested a method by which surface tension could be reversibly altered to examine its effect on the microvasculature.

Surface tension was increased in the experimental lobes by cooling from room temperature to $17^{\circ} \mathrm{C}(8)$ by ventilating with cool gas and blowing cold air onto the lung surface. Temperature was measured at multiple sites on the lung surface. Ventilation during this time was carried out with large tidal volumes ( $>50 \%$ of total lung capacity) at low FRC for $30 \mathrm{~min}$ (7) while vascular pressures were held at $0 \mathrm{~cm} \mathrm{H}_{2} \mathrm{O}$. At the respiratory rates employed (20-25 times per minute) complete emptying to resting volume by passive deflation did not occur, producing an end-expiratory volume always slightly greater than residual volume. After measurements in cooled, stiff lungs, surface tension was restored by holding the experimental lobe in inflation for $30 \mathrm{~min}$ while rewarming above $26-28^{\circ} \mathrm{C}(8)$.

Isogravimetric pressure (Pisog) was measured at the same lung volume after surface tension had been increased, and contrasted with that measured under control conditions before and after the change. Pisog is that level of vascular hydrostatic pressure at which lung weight remains constant. At this level, both Ppmv and the transmural osmotic gradient are balanced by microvascular pressure (9). When osmotic pressures are constant, changes in microvascular pressure reflect the changes in Ppmv. Pisog was determined experimentally by raising or lowering $\mathrm{Ppa}$ and $\mathrm{Ppv}$ until a microvascular pressure was found that resulted in no net change in transvascular fluid flux as determined by a constant lung weight over a period of $5 \mathrm{~min}$. Ppa and Ppv were alternately raised above and then lowered below the likely Pisog in three or four decreasing steps until Pisog was found. We estimate the method was accurate to $\pm 2 \mathrm{~cm} \mathrm{H}_{2} \mathrm{O}$, because if vascular pressures were altered from $\mathrm{Pisog}$ by $>2 \mathrm{~cm} \mathrm{H}_{2} \mathrm{O}$ lung weight changes were apparent.

Statistical comparison was performed with Student's paired $t$ test.

Pisog was measured with normal and increased surface tension at 2 vol corresponding to two initial Palv.
Palv $=30 \mathrm{~cm} \mathrm{H}_{2} \mathrm{O}$ (total lung capacity). In nine animals, Pisog was determined under control conditions when Palv was reduced to $30 \mathrm{~cm} \mathrm{H}_{2} \mathrm{O}$ after inflation to $35 \mathrm{~cm} \mathrm{H}_{2} \mathrm{O}$. After cooling and ventilating the lobes at a high tidal volume and low FRC, control lung volume was reestablished by adjusting Palv after initial slight overexpansion. Pisog was remeasured. The experimental lobe was then rewarmed while holding it at a high inflation volume. After reestablishing control lung volume, Pisog was measured again.

Palv $=10 \mathrm{~cm} \mathrm{H} \mathrm{H}_{2} \mathrm{O}(75-85 \%$ total lung capacity $)$. In three animals, the identical protocol was followed but the lung volume produced on the deflation limb by a base-line Palv of $10 \mathrm{~cm} \mathrm{H}_{2} \mathrm{O}$ was used as the control condition.

To evaluate the effect that either cooling or ventilating the lobe at low FRC might have on the development of edema, the same protocol was followed in two control animals where the lobes were either cooled without ventilation or ventilated at a low FRC without cooling, with subsequent determination of Pisog.

\section{RESULTS}

Palv $=30 \mathrm{~cm} \mathrm{H}_{2} \mathrm{O}$. After cooling and ventilating the lobes with a high tidal volume at low FRC, the mean Palv $\pm S D$ required to inflate to control lung volumes increased from 30 to $50 \pm 5 \mathrm{~cm} \mathrm{H}_{2} \mathrm{O}(P<0.01)$ (Fig. 1). After rewarming, the control lung volume was established by a Palv of $32 \pm 2 \mathrm{~cm} \mathrm{H}_{2} \mathrm{O}$. This was significantly different from the cooled state $(P<0.01)$ but not from control. With increasing surface tension, Pisog relative to Palv changed from a mean of $-0.8 \pm 1.8$ to $-13.6 \pm 3.6$ $\mathrm{cm} \mathrm{H}_{2} \mathrm{O}(P<0.01)$ (Fig. 2). With restoration of surface tension towards normal, Pisog relative to Palv returned to $-2.2 \pm 1.0 \mathrm{~cm} \mathrm{H}_{2} \mathrm{O}$ and was not significantly different from the control value $(P>0.05)$.

Palv $=10 \mathrm{~cm} \mathrm{H}_{2} \mathrm{O}$. With increasing surface tension, the Palv required to establish control lung volumes increased from $10.0 \pm 0$ to $23.3 \pm 2.1 \mathrm{~cm} \mathrm{H}_{2} \mathrm{O}(P<0.01)$ (Fig. 2). Relative to Palv, Pisog decreased from a mean of $-0.3 \pm 0.6 \mathrm{~cm} \mathrm{H}_{2} \mathrm{O}$ to $-10.3 \pm 2.3 \mathrm{~cm} \mathrm{H}_{2} \mathrm{O}(P<0.01)$ with increasing surface tension (Fig. 2). When the lung was rewarmed, Palv returned to $11.7 \pm 1.5 \mathrm{~cm} \mathrm{H}_{2} \mathrm{O}$ and Pisog relative to Palv returned to $1.7 \pm 1.5 \mathrm{~cm} \mathrm{H}_{2} \mathrm{O}$ (Figs. 1 and 2).

Although high Palv were necessary to distend the

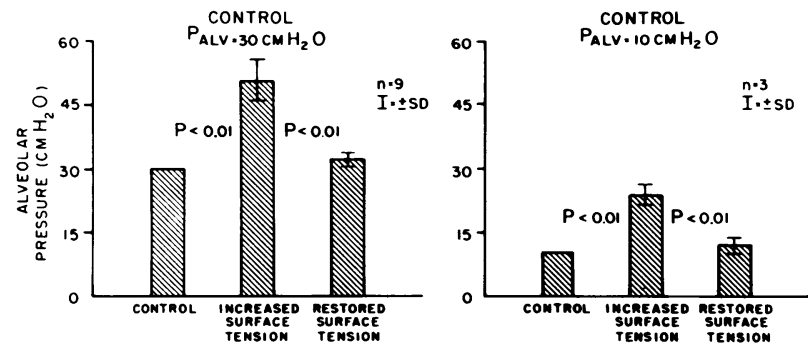

Figure 1 Palv changes with alterations of alveolar surface tension at 2 lung vol produced by different Palv. 

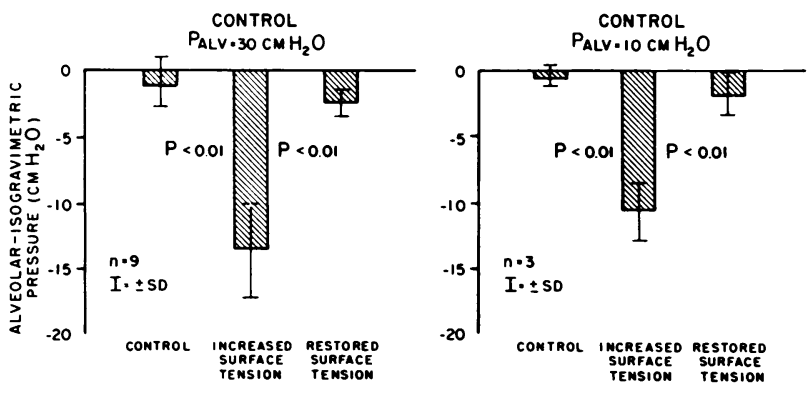

Figure 2 Isogravimetric pressure changes relative to Palv with alterations of alveolar surface tension at 2 lung vol produced by different Palv.

experimental lobes, no interstitial emphysema or perihilar leaks were apparent.

\section{DISCUSSION}

Several authors have predicted, on theoretical grounds, that increasing alveolar surface tension should favor fluid transudation by lowering the extramicrovascular fluid pressure $(5,6,10)$. These experiments test this prediction by comparing Pisog in normal lungs with that in the same lungs after recoil has increased presumably because of an altered surface tension.

Faridy et al. (7) and subsequently others $(8,11-13)$ have demonstrated that at room temperature, the compliance of excised lungs falls during ventilation with large tidal volumes at low FRC. Nagao et al. (8) have documented that in the rabbit this effect occurs only below temperatures of $25-26^{\circ} \mathrm{C}$. The decreased compliance is thought to be secondary to an alteration or depletion of surface active material because similar effects of cooling, or ventilating at low FRC, are not observed on the saline pressure volume curves $(7,8)$. Apparently, the effect primarily represents a physical aggregation of surfactant occurring during the film collapse that results from high film pressure at low endexpiratory volumes. Respreading may then fail to occur on subsequent inflations, functionally depleting the surface lining layer (8). The process is readily reversible, as holding the lung in inflation above room temperature for $1 \mathrm{~h}$ has been shown to restore normal compliance $(7,11)$.

Alveolar atelectasis or exaggerated wall folding, with overdistention of open alveoli could have partially accounted for the diminished compliance observed with cooling and hyperventilating. However, this would likely arise secondarily to an increased surface tension. In addition, several observations make the possibility of widespread atelectasis unlikely. First, lung volume and compliance measurements were made after distension of the lung to larger than control volumes. Second, there was no evidence of macroscopic atelectasis at any time during the experiment. Third, microscopic examination of the lungs subjected to this pattern of ventilation has failed to show atelectasis or other pathology that could account for the observed alterations in compliance (12).

When cooling the lobes to $17^{\circ} \mathrm{C}$ without ventilating, or ventilating with high tidal volumes at low FRC without cooling, no change in either the Palv required to produce control lung volumes or in Pisog was apparent. Although too few studies were performed to statistically evaluate these results, it would appear that neither cooling nor ventilating alone altered surface tension or transvascular fluid flux.

Lung volume was held constant in this experiment and Pisog was expressed relative to Palv. This enables the results obtained in an open-chested dog to be related to the conditions existing in a closed-chest situation. The intact condition differs in that lung distension is the result of the transpulmonary pressure generated by negative intrapleural pressure. However, when all pressures are expressed with respect to a common reference, Palv, positive and negative pressure lung inflation can be directly compared. Palv can appropriately be used as the common reference because it is likely that the alveolar microvessels, which are influenced by Palv, are a major source of lung edema. Pisog was equal to or less than Palv at the bottom of the lungs in these studies. Thus, it is reasonable to ask whether the alveolar microvessels were closed, as predicted in zone I conditions. It has been shown that the lung can be perfused high into zone I (2). Additionally, the Palv necessary to stop flow is normally $5-7 \mathrm{~cm} \mathrm{H}_{2} \mathrm{O}$ higher than the Ppa at the base of the lung $(3,4)$. This suggests that some microvessels, particularly those located in the corners of alveoli, remain patent.

When surface tension was increased and the lung was held at a constant volume, Pisog fell relative to the Palv. The fall in Pisog can be interpreted to indicate that a fall in fluid Ppmv has occurred with the increase in alveolar surface tension. The increase in the retractive force of the fluid film lining the alveolus likely results in transmission of a more negative pressure either directly to the alveolar perimicrovascular space or indirectly by causing more negative pressures in the perivascular spaces. Much of the increase in transpulmonary pressure in the stiff lungs apparently was transmitted to Ppmv. For example, when transpulmonary pressure increased by $20 \mathrm{~cm} \mathrm{H}_{2} \mathrm{O}$, Pisog dropped by $14 \mathrm{~cm} \mathrm{H}_{2} \mathrm{O}$.

The actual site of the increased fluid transudation cannot be determined. Both the alveolar septal and corner vessels, as well as the larger extra-alveolar vessels would be under increased radial traction. Extraalveolar vessels are capable of leakage (14) and their transvascular gradient could be increased by surfactant 
depletion although their distension has been most closely linked to increases in lung volume. Additionally, the more negative perimicrovascular fluid pressure in the corners of alveoli could be partially transmitted through the interstitial fluid channels of the alveolar walls to affect transudation from other parts of the alveolar microvasculature.

Although the permeability of these vessels might also be increased by increased radial traction or increased transmural pressure, the isogravimetric method used in these experiments measures only changes in net transvascular driving forces (9). However, perivascular osmotic pressure and vessel reflection coefficients also contribute to alterations in Pisog. Thus, interpreting changes in Pisog as solely representing change in Ppmv may be somewhat in error.

The association of mechanical ventilation and pulmonary edema was made in 1968 (15). It has been repeatedly described in both clinical and animal studies (16-19). Webb and Tierney (19) have found that alveolar and perivascular edema resulted from ventilation with high inspiratory pressures at low end-expiratory volumes. They postulated that surfactant depletion could potentially explain the edema. The effect of surfactant depletion favoring edema formation might apply to both the infant and adult respiratory distress syndromes. In these settings, both qualitative and quantitative abnormalities in surfactant have been documented (20-23) and edema is uniformly observed $(21,24)$. Our studies provide support for this hypothesis by showing that experimentally induced increases in surface tension favors edema formation.

\section{ACKNOWLEDGMENTS}

The authors are indebted to Ms. Patty Ross and Ms. Diane Johnson for secretarial assistance.

This study was supported by the General Research Fund of the Veterans Administration Hospital and National Institutes of Health grants HL-20652 and HL-20690.

\section{REFERENCES}

1. Guyton, A. C., H. J. Granger, and A. E. Taylor. 1971. Interstitial fluid pressure. Physiol. Rev. 51: 527-563.

2. Lloyd, T. C., Jr., and G. W. Wright. 1960. Pulmonary vascular resistance and vascular transmural gradient. J. Appl. Physiol. 15: 241-245.

3. Bruderman, I., K. Somers, W. K. Hamilton, W. H. Tooley, and J. Butler. 1964. Effect of surface tension on circulation in the excised lungs of dogs. J. Appl. Physiol. 19: 707-712.

4. Pain, M. C. F., and J. B. West. 1966. Effect of the volume history of the lung on distribution of blood flow. J. Appl. Physiol. 21: 1545-1550.

5. Pattle, R. E. 1955. Properties, function and origin of the alveolar lining layer. Nature (Lond.). 175: 1125-1126.

6. Clements, J. A. 1961. Pulmonary edema and permeability of alveolar membranes. Arch. Environ. Health. 2: 280-283.
7. Faridy, E. E., S. Permutt, and R. L. Riley. 1966. Effect of ventilation on surface forces in excised dogs' lungs. $J$. Appl. Physiol. 21: 1453-1462.

8. Nagao, K., R. Ardila, M. Sugiyama, and J. Hildebrandt. 1977. Temperature and hydration: factors affecting increased recoil of excised rabbit lung. Respir. Physiol. 29: 11-24.

9. Pappenheimer, J. R., and A. Soto-Rivera. 1948. Effective osmotic pressure of the plasma proteins and other quantities associated with the capillary circulation in the hindlimbs of cats and dogs. Am. J. Physiol. 152: 471-491.

10. Guyton, A. C., A. E. Taylor, R. E. Drake, and J. C. Parker. 1976. Dynamics of subatmospheric pressure in the pulmonary interstitial fluid. In Lung Liquids. Ciba Symposium 38. Elsevier/North Holland, Amsterdam. 77-95.

11. McClenahan, J. B., and A. Urtnowski. 1967. Effect of ventilation on surfactant and its turnover rate. J. Appl. Physiol. 23: 215-220.

12. Raimondi, A. C., G. R. Massarella, and N. B. Pride. 1971. The effects of ventilation on the elastic recoil of excised dogs' lungs. Respir. Physiol. 12: 205-217.

13. Wyszogrodski, I., K. Kyei-Aboagye, H. W. Taeusch, and M. E. Avery. 1975. Surfactant inactivation by hyperventilation: conservation by end-expiratory pressure.J. Appl. Physiol. 38: 461-466.

14. Albert, R. K., S. Lakshminaryan, T. W. Huang, and J. Butler. 1978. Fluid leaks from extra-alveolar vessels in living dog lungs. J. Appl. Physiol. Respir. Environ. Exercise Physiol. 44: 759-762.

15. Sladen, A. M., B. Laver, and H. Pontoppidan. 1968. Pulmonary complications and water retention in prolonged mechanical ventilation. N. Engl. J. Med. 279: 448-453.

16. Caldini, P. J., J. D. Leith, and M. J. Brennan. 1975. Effect of continuous positive pressure ventilation (CPPV) on edema formation in dog lung. J. Appl. Physiol. 39: $672-679$.

17. Demling, R. H., N. C. Staub, and L. H. Edmunds, Jr. 1975. Effect of end-expiratory pressure on accumulation of extravascular lung water. J. Appl. Physiol. 38: 907-912.

18. Woolverton, W. C., K. L. Brigham, and N. C. Staub. 1973. Effect of continuous positive airway pressure breathing on pulmonary fluid filtration and content in sheep. Physiologist. 16: 490.

19. Webb, H. H., and D. F. Tierney. 1974. Experimental pulmonary edema due to intermittent positive pressure ventilation with high inflation pressures. Protection by positive end-expiratory pressure. Am. Rev. Respir. Dis. 110: 556-565.

20. Petty, T. L., O. K. Reiss, G. W. Paul, G. W. Silvers, and N. D. Elkins. 1977. Characteristics of pulmonary surfactant in adult respiratory distress syndrome associated with trauma and shock. Am. Rev. Respir. Dis. 115: 531-536.

21. Farrell, P. M., and M. E. Avery. 1975. Hyaline membrane disease. Am. Rev. Respir. Dis. 111: 657-688.

22. Ashbaugh, T., D. B. Bigelow, T. L. Petty, and B. E. Levine. 1967. Acute respiratory distress in adults. Lancet. II: 319-323.

23. Henry, J. N., A. H. McArdle, G. Bounous, L. G. Hampson, H. J. Scott, and F. N. Gurd. 1967. The effect of experimental hemorrhagic shock on pulmonary alveolar surfactant. J. Trauma. 7: 691-726.

24. Lamy, M., R. J. Fallat, E. Koeniger, H-P. Dietrich, J. L. Ratliff, R. C. Eberhart, H. J. Tucker, and J. D. Hill. 1976. Pathologic features and mechanisms of hypoxemia in adult respiratory distress syndrome. Am. Rev. Respir. Dis. 114: $267-284$. 